\title{
Pavement Life Variation with Material Characteristics, Road Profiles and Environmental Effects
}

\author{
Rosnawati Buhari", Munzilah Md Rohani ${ }^{\#}$, Saifullizam Puteh ${ }^{*}$ \\ ${ }^{\#}$ Faculty of Civil and Environmental Engineering, Universiti Tun Hussien Onn Malaysia, Batu Pahat, Johor, Malaysia. \\ E-mail:rosna@uthm.edu.my ${ }^{1}$, munzilah@uthm.edu.my ${ }^{2}$
}

*Faculty of Technical and Vocational Engineering, Universiti Tun Hussien Onn Malaysia, Batu Pahat, Johor, Malaysia. E-mail:saifull@uthm.edu.my

\begin{abstract}
Long-term performance of pavements is dependence on several aspects including design and method of construction, vehicles loading and environmental conditions along their service life. The pavement response to these aspects is mostly based on the stiffness characteristic of the materials. The most significant stiffness property is the resilient modulus that is based on the strain under loads, and several factors include roughness of road profile, soil property, soil type and stress state. This study focuses on the simulation of the pavement performance by considering pavement material and vehicle characteristic, road roughness, and temperature variations. The vehicle-road interaction is the main focus. It includes analysis of the integration of damage consequence by the static and dynamic loads of the vehicle fleet on the structural variability of the pavement. Meanwhile, other factors such as temperature influencing the modulus degradation of the bituminous material is also included. As a result, all factors were significantly contributed to the life of the pavement.
\end{abstract}

Keywords — pavement performance; vehicle-road interaction; Q-truck model; fatigue and rutting; primary response.

\section{INTRODUCTION}

The analysis of pavement structure is complicated as it involves many factors include an external variation of tire loads, load pressures, material properties, climate, and environment. It is more complicated as involves multilayer system. The studies on Pavement Performance Model (PPM) have been performed since the 1980s involved analytical and mechanistic procedures [1]. The analytical method is capable of calculating fundamental parameter such as stress, strain, and deflection in a multi-layered system when subject to external loads, while the mechanistic procedure is capable of translating an analytical calculation of pavement response into performance. Ultimately, the concern is not with stresses and strains but with how these stresses and strains related to field performance [1]-[8].

Currently, mechanistic-empirical design approach has been developed which consider the changes of climate and water content in the road structure and sub-grade throughout the pavement life [7]-[9]. The Enhanced Integrated Climatic Model (EICM) was designed to generate patterns of rainfall, and solar radiation. It is also taking into account the drainage of the base layer in measuring the amount of water that flows into the subgrade by infiltration from the road surface and base layer. Other than that, numerical analysis method also used to analyze the relationship between stress-strain and deflection to fatigue and rutting failure [10]. Vehicles load and tire pressure were concluded as the factor caused by failure instead elastic modulus of the layer materials. Using this method, pavement structure was design by varying the modulus of each material and layer thicknesses.

The PPM in this study contains a step of predicting the primary response from the loads, determine stiffness modulus, examine damage mechanisms and finally accumulate the level of pavement damage. This is the last step, once the failure mechanism was achieved. Otherwise, it ends at the step of degrading the elasticity of the bituminous material. This model is capable of predicting longitudinal roughness, fatigue cracking and rutting of a pavement consisting of an adjacent layer, an unbound subbase layer, and subgrade. Generally, to simulate the deterioration over time, the model makes use of an incremental recursive procedure; that is, the output from each time increment becomes the input for the next time increment.

Meanwhile, Collop in the year 1994 was developed a modulus degradation model using back-calculation procedures [4]. The ARRL supplied the data of surface 
deflection. In his model, the asphalt modulus degradation law is a correlation between the modulus of elasticity of the bituminous material and fatigue. The inverse procedure was used to get the stiffness modulus that provided a surface deflection that suit with the measured surface deflection. Further review of back-calculation procedures and model developments can be found in Collop study [4]. The correlation between the elasticity value of the asphalt concrete and fatigue cracking is defined as:

$$
\begin{gathered}
\frac{E_{m}}{E_{m}^{0}}=E X P\left\{\log _{e}\left(\frac{E_{m}}{E_{m}^{0}}\right)_{c} D\right\} D \leq 1 \\
\frac{E_{m}}{E_{m}^{0}}=\left(\frac{E_{m}}{E_{m}^{0}}\right)_{c} D>1
\end{gathered}
$$

The $E_{m} / E_{m 0}$ is the decreasing in modulus of elasticity of the asphalt concrete, $D$ is an accumulate fatigue cracking damage, $\left(E_{m} / E_{m 0}\right)_{C}$ is a constant, that is, the level of modulus reduction that correspond been reached $(D=1)$. It may be equal to 0.2 [4]. Using this model, fatigue of the bituminous material is calculated using the effective stiffness modulus. The strain at the base of the asphalt layer is used as an indicator of fatigue that was assumed to be initiated at the base course and propagates slowly upward to the road surface.

The resilient modulus defined as a function of stress level is a common characteristic that is widely used for the analysis and design of road structures recently. Therefore, it is essential to evaluate the stresses mobilized within road sub-layers upon loading as well as other significant factors. Conventionally, the resilient modulus is an engineering property evaluated by the Californian Bearing Ratio (CBR). Currently, several analytical models for evaluating resilient modulus are focused on stress-dependency. The behavior of granular soils has been found to vary primarily as a function of the bulk stress, while the applied deviator stress is found to be more critical for fine-grained soils. The optimum moisture content of a granular layer is recorded to be between 6 and 9\%. Applying these values, the optimum resilient modulus of granular mixes can be calculated using the following equation [7];

$$
M_{\text {Ropt }}=2555 C B R^{0.64}
$$

The $C B R$ value is determined by correlating the moisturedensity and $C B R$ curves [13]. Poisson ratio for unbound material approximately from 0.3 for crushed material to 0.4 for gravels or sands [14]. Other than that, Widodo et al. noticed that CBR value may determine using bearing capacity equation without considering confining pressure of the soil.

Cracking of the bituminous layers is caused by a tensile strain that is developed in bound layers after several loads pass and continuously propagated throughout the bituminous layers. Other than that loads cracking also influenced by temperature variations and construction method. The correlation of fatigue life and the tensile strain is as follows:

$$
N_{f}=k_{1}\left(\varepsilon_{t}\right)^{-k_{2}}
$$

The $N_{f}$ is some loads to initiate fatigue cracking, $\varepsilon$ t is tensile strain under the bituminous layer, and $k_{1}$ and $k_{2}$ are constants. Also, permanent deformation occurs when material from under the wheel path of a truck flow to form a groove or rut. The general correlation between rutting and vertical strain on top of the subgrade is as follows:

$$
N_{r}=k_{4}\left(\varepsilon_{c}\right)^{k_{5}}
$$

The $N_{r}$ is an allowable number of vehicles to failure, $\varepsilon_{c}$ is compression strain on the subgrade layer, $k_{4}$ and $k_{5}$ are constants. The values of $k_{4}$ and $k_{5}$ can be calibrated to match the field observations. The value of $k_{5}$ vary from 1.85 to 7.14 is based on the layer design and the test condition. A $k_{5}$ value equal to 3.57 has been used [13]. Evaluation of pavement response to vehicular loading is an essential consideration to predict the most accurate pavement performance as well as to guarantee optimum performance since the design life of the pavement. The Peak Influence function (PIFM) and Influence function method (IFM) will be used in this study based on the previous study [14]-[16].

The pavement condition and material properties gradually change throughout the lifetime as the pavement is subjected to a succession of various magnitudes of load pulses and various time intervals between loading pulses. Moreover, it depends on the details of the traffic loads, climatic variation, a variation of the pavement structure and the material properties in time. It has been shown that the damage caused by each magnitude of load pulse at various time intervals can be predicted by the results of simple loading test, according to a linear hypothesis, such as Miner's rule [17]. This statistical law can be applied irrespective of the pavement course or the distress mechanism involved, cracking or permanent deformation. The parameter $D$ referred to as accumulation of damage varies between 0 and 1 , where $D=0$ for the undamaged material and $D=l$ for failed material.

$$
D=\sum_{i=1}^{j} \frac{N^{(i)}}{N_{f}^{(i)}}
$$

The $N^{(i)}$ is the number of loads at a given strain level, $\mathrm{N}_{\mathrm{f}}^{(\mathrm{i})}$ is the number of loads to failure at that strain level, and $j$ is the several strain levels.

\section{MATERIAL AND METHOD}

\section{A. Simulation of Pavement Performance Model using MATLAB Software}

The simulation work followed the flowchart as illustrated in Fig. 1. As shown in the figure, in overall, the PPM used an incremental-recursive procedure to simulate the damage propagation over time. The output from each time increases recursively as the input in the next time increases. The incremental process is applied to individual points along the longitudinal road. The simulation starts with providing road profiles which interact with the wheel loads and a dynamic load were generated at this stage. Other than the wheel loads the speed of the vehicle is required. The cycle is based on a time-stepping algorithm that requires repeated application of force to the surface, updates in temperature, recalculating the critical response as well as, damage mechanism. Thus, the 
accumulation of damage is computed to degrade the asphaltic concrete stiffness modulus and road profile. This applies to all cases. For that purpose, a computer programming was developed using MATLAB software for simulating the performance of the pavement from the beginning of trafficking until the roads fail.

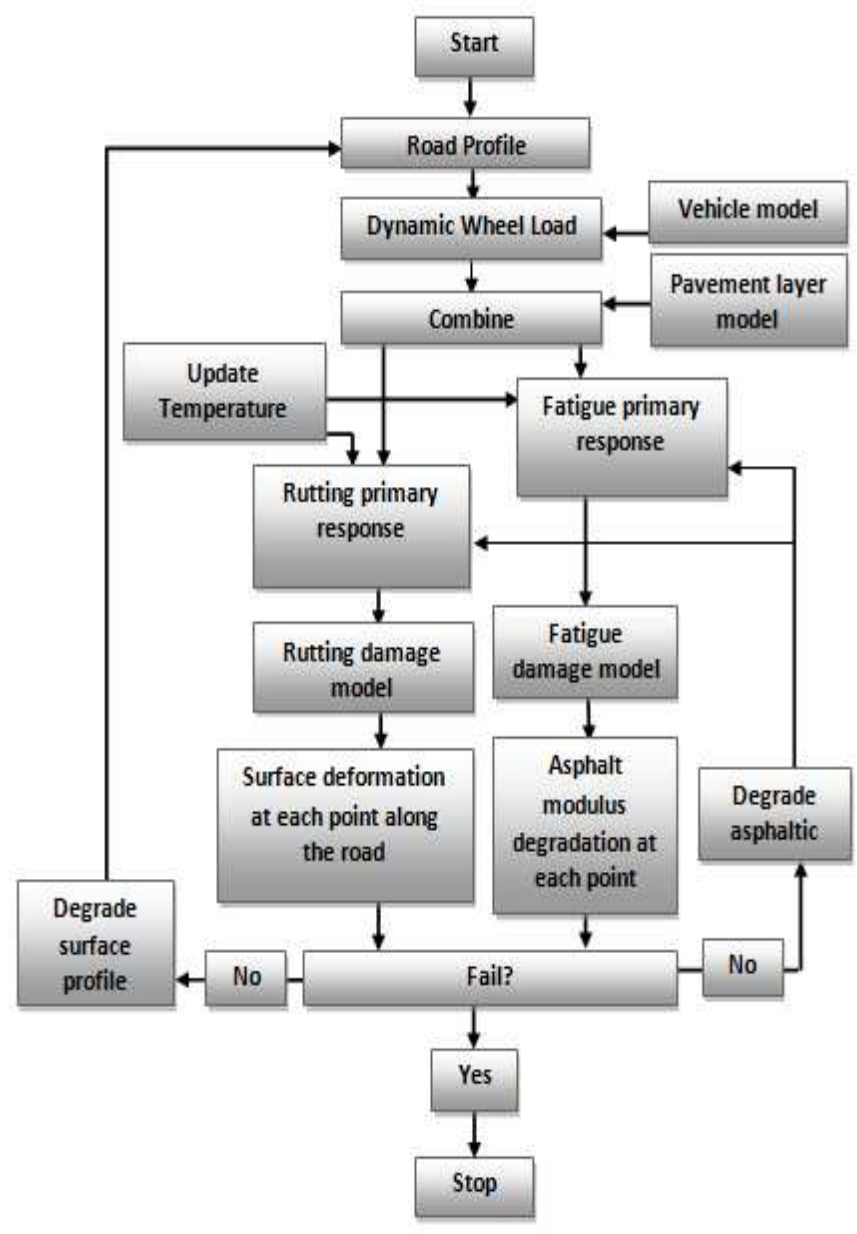

Fig. 1. Pavement Performance Model

\section{B. Road and pavement discretization}

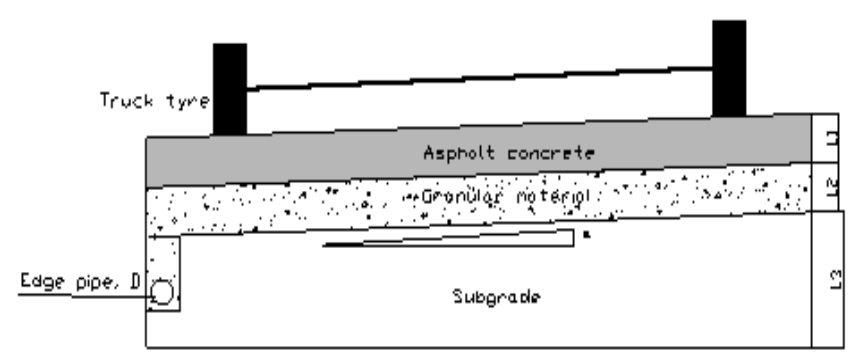

Fig. 2 Pavement Structure

Fig. 2 shows the schematic figure illustrating the longitudinal road space distance and cross-sectional pavement structures as well as space cells for finite difference method for $P P M$ predictions. A $500 \mathrm{~m}$ longitudinal road profiles were discretized into several block spaces with equal width and length. For along the road structure, drainage pipe was installed at the left edge side. However, for predicting $P P M$ without precipitation, this drainage pipe is omitted. The water flow was simulated using the finite difference method. Thus, the cross-section of the pavement structure was discretized into several spaces distanced. The diameter of the loading area is derived from the tires is $0.3 \mathrm{~m}$, which means that several points on the surface are loaded and degrade throughout the time of simulation.

\section{Material Characterization}

The environmental factor considered in the $P P M$ is a temperature that may affect the elasticity of the asphaltic material. Climate affects the performance and mechanical properties of pavement components and to pavement structures ability to withstand traffics forces especially from good heavy vehicles. The materials used in the pavement structure were based on the JKR/SPJ/2008, a Specification for Road Works in Malaysia [18] and Manual of Pavement Design (Technical Order (Road) 5/85 [Amendment 2013] [19]. Table 1and Table II gives the material properties that have been used in the pavement structure model.

TABLE I

MATERIAL PROPERTIES

\begin{tabular}{|c|c|}
\hline \multirow{4}{*}{ 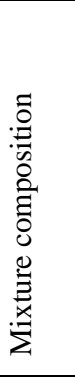 } & Parameters \\
\hline & $\begin{array}{l}\text { Volume of void }(\mathrm{Vv})=5 \% \\
\text { Volume of bitumen }(\mathrm{Vb})=7.5 \% \\
\text { Penetration of the bitumen, }(\mathrm{Pi})=60 \% \\
\text { Temperature varies }\end{array}$ \\
\hline & $\begin{array}{l}\text { CBR value CBR of sub-base layer }=60 \% \\
\text { Optimum moisture content }=8 \%\end{array}$ \\
\hline & $\begin{array}{l}\text { CBR of subgrade soil }=5 \% \\
\text { Optimum moisture content }=12 \%\end{array}$ \\
\hline 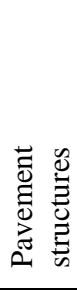 & $\begin{array}{l}\text { The thickness of the surface bituminous material }=0.2 \mathrm{~m} \\
\text { The Poisson ratio of the surface bituminous material } \\
=0.35 \\
\text { The thickness of base layer }=0.2 \mathrm{~m} \\
\text { The Poisson ratio of base layer material }=0.4 \\
\text { The thickness of the sub-base granular material }=0.2 \mathrm{~m} \\
\text { The Poisson ratio of the sub-base granular material }=0.4\end{array}$ \\
\hline
\end{tabular}

All the parameter values are constant throughout the simulation except the temperature which ranges from $27^{\circ} \mathrm{C}$ to $30^{\circ} \mathrm{C}$; that is the monthly mean temperature from daily temperature data ranges of $21.7^{\circ} \mathrm{C}$ to $34^{\circ} \mathrm{C}$. The flexible pavement used consists of $0.2 \mathrm{~m}$ bituminous layers over a $0.2 \mathrm{~m}$ unbound sub-base. The thicknesses are the general thickness used for road construction in Malaysia that is based on the Standard and Construction Layer thicknesses (JKR/SPJ/2008-S4).

The loads are applied in the circular area. Each layer has infinite width while the thicknesses are finite except for the subgrade layer. Every layer is homogeneous, linear elastic and isotropic, characterized by elastic modulus and Poisson's ratio ranges from 0.3 to 0.5 for non-cohesion and cohesive soil respectively. [20]. A typical value was taken to be 0.4 . The Poisson's ratio of the asphaltic concrete, subbase and subgrade are $0.35,0.4$ and 0.4 respectively. 
Bitumen grade $60 / 70$ was used, and the percentage volume of the bitumen is about $7.5 \%$.

TABLE II

PAVEMENT PROPERTIES VARIATIONS [ROAD 1 USING THE VALUE IN BRACKET]

\begin{tabular}{|c|c|c|c|c|}
\hline Layer & $\begin{array}{c}\text { Thickness } \\
\text { h, (mm) }\end{array}$ & $\begin{array}{c}\text { Air void, } \\
v_{v,(\%)} \\
\end{array}$ & $\begin{array}{c}\text { Binder, } \\
v_{b,(\%)}\end{array}$ & $\begin{array}{c}\text { Modulus } \\
\text { (GPa) }\end{array}$ \\
\hline \multirow{5}{*}{$\begin{array}{l}\text { Asphalt } \\
\text { concrete } \\
\text { layer }\end{array}$} & 150 & (4) & 4 & \multirow{5}{*}{$E_{1}$} \\
\hline & (200) & 6 & 6 & \\
\hline & 250 & 8 & (8) & \\
\hline & 300 & 10 & 10 & \\
\hline & 350 & 12 & 12 & \\
\hline \multirow{3}{*}{$\begin{array}{l}\text { Granular } \\
\text { Sub-base }\end{array}$} & \multirow{3}{*}{200} & \multirow{3}{*}{ - } & \multirow{3}{*}{-} & $\left(E_{2}=0.1 E_{1}\right)$ \\
\hline & & & & $E_{2}=0.02 E_{1}$ \\
\hline & & & & $E_{2}=0.01 E_{1}$ \\
\hline $\begin{array}{l}\text { Subgrade } \\
\text { Soil }\end{array}$ & $\infty$ & - & - & $E_{3}(\mathrm{CBR}-5 \%)$ \\
\hline
\end{tabular}

\section{Vehicle Model}

A linear 'quarter-truck' model has been used traveling along $100 \mathrm{~m}$ length of road with varying levels of roughness. Detail of the quarter truck model was referring to previous work [21]-[23]. The road profiles as shown in Fig. Three are used. The height of road profile is representing pavement roughness. The sample interval for all road profiles is $0.1 \mathrm{~m}$, and International Roughness Index is 2 for all profiles. The vehicle data as shown in Fig. 4 has been used. The total vehicle that considered in this study is 1200 vehicles, and the speed was assumed to be varied. Overall vehicle speed ranges from 47 to $120 \mathrm{~km} / \mathrm{h}$ with the dominant at $75 \mathrm{~km} / \mathrm{h}$. The dynamic load generated by the single tire vehicle model that responded to the road profile was applied to the road structures. The diameter of the contact area of the load applied equally to $300 \mathrm{~mm}$.

\section{E. Climatic Data}

The climatic data were obtained from the Department of Meteorology Malaysia for the year 2009. This includes hourly temperature and rainfall intensities. The temperature and rainfall data were managed systematically and summarized in a computerized database. Statistical analysis was performed to measure monthly averages and standard deviations. The daily average temperatures are given in Fig. 5. It shows that the temperature ranges from $27^{\circ} \mathrm{C}$ to $30^{\circ} \mathrm{C}$.

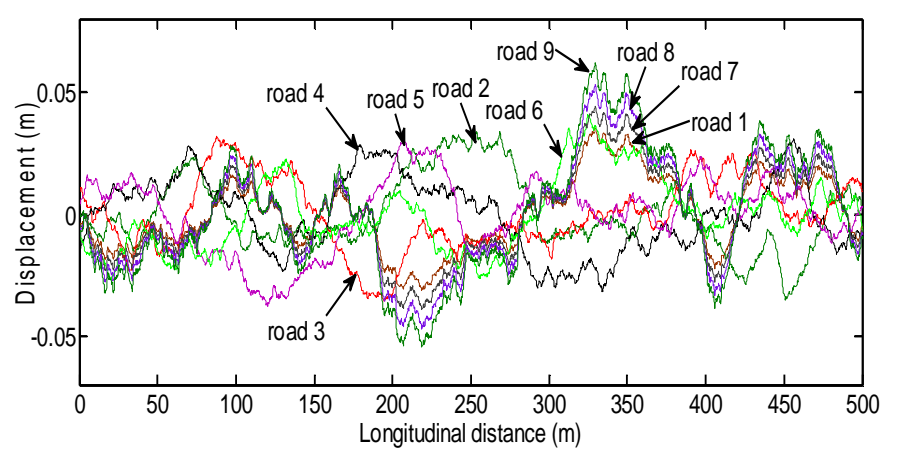

Fig. 3 Road Profiles

\section{F. Iteration}

The simulation starts by characterized the road length and pavement structures. The length of pavement surface is divided into many equally spaced subsections of 0.1 meters. The incremental process is applied to the individual points along the longitudinal road.

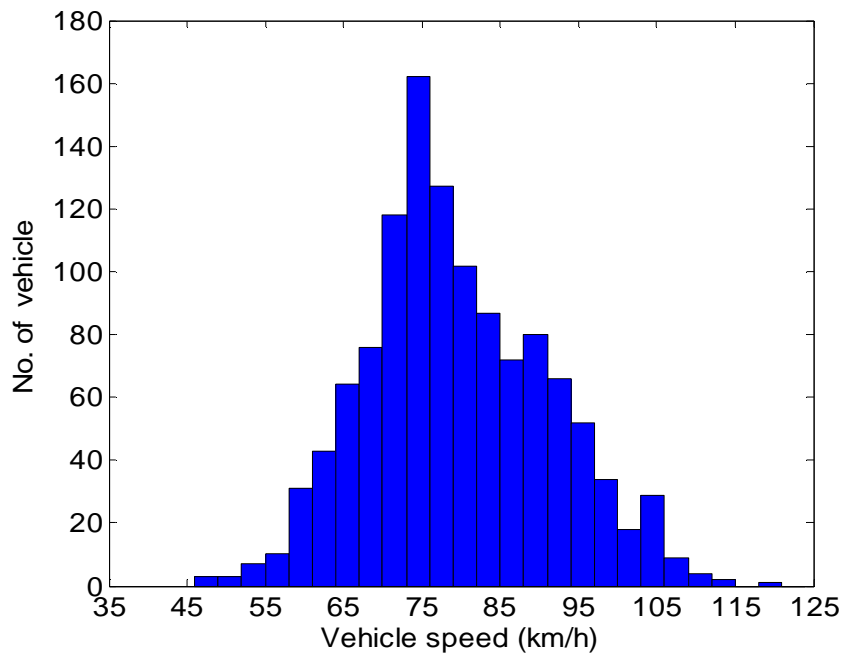

Fig. 4 Daily number of vehicles versus speeds

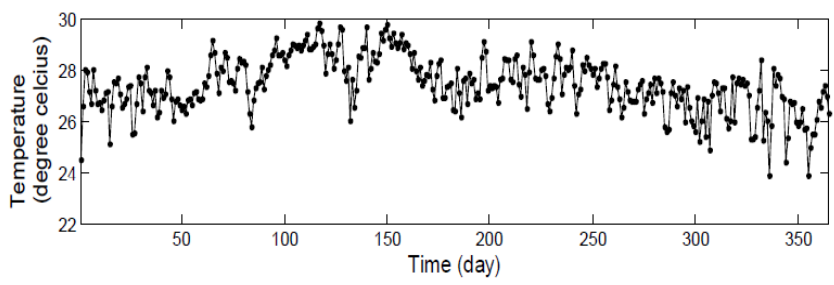

Fig. 5 Daily temperature

Dynamic tire forces of the vehicles traveling along the road are generated using time domain vehicle simulation. The dynamic tire forces are then combined with primary response influence functions to get a response at all points. The pavement response is calculated using the linear elastic theory. The tensile strain just below the asphaltic layer and compression strain on the sub-grade layer are computed at a location directly below the mid-point of the full area from each loading condition by changing the quarter-truck model properties. The first response histories are then transformed into two damage mechanisms that are, fatigue and rutting using determined damage model.

The number of allowable cycles to failure is used to determine the increment of damage at discrete points along the road due to load passes. For each time increment, the truck-road interaction simulation program was run for each type of truck model. The increments of damage from tandem and tri-axles are computed by multiplying the increment of damage from a single axle by two and three, respectively. The total monthly increment of damage was calculated by multiplying the increment of damage from each axle by the monthly number of axles, respectively. Following that, the accumulation of total damage at discrete points along the road from all vehicles was then computed using Miners Law. 
Using the results, the asphaltic material modulus is degraded to reflect fatigue damage. The new asphaltic layer elastic modulus was then determined for the next time increment. Meanwhile, the road surface profile was updated to reflect the rutting damage.

\section{RESULTS AND DISCUSSION}

\section{A. Prediction for different road profiles}

Fig. 6 shows the whole life pavement performance of road 1 to road 9. As shown in the figure, Road 1 to Road 6 is the road profiles generated with IRI=2 and the IRI for Road 7, Road 8 and Road 9 are 2.5, 3 and 3.5, respectively.

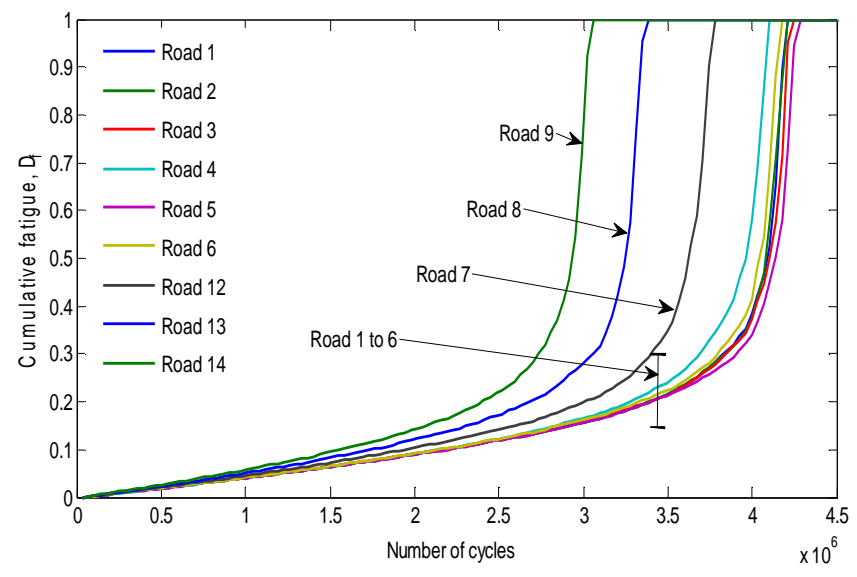

(a)

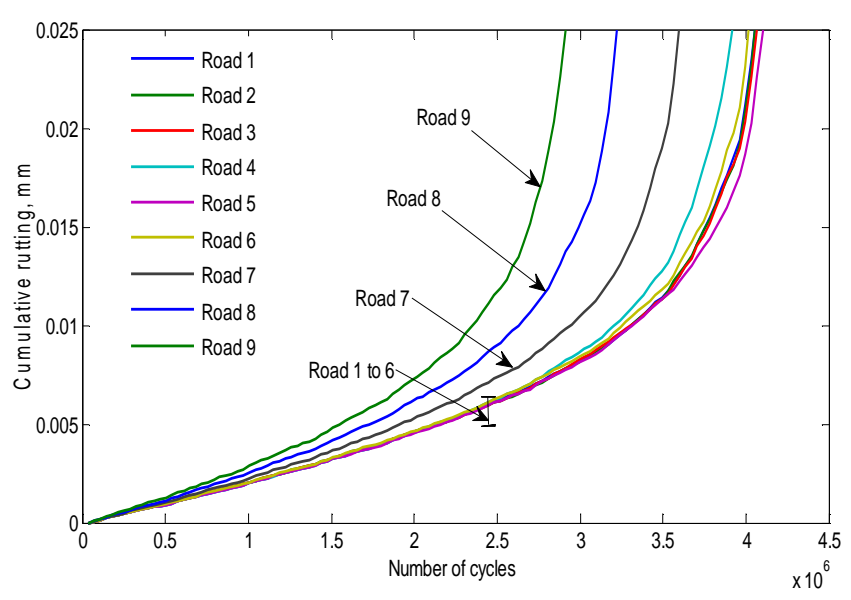

(b)

Fig. 6 Cumulative damages, (a) fatigue and (b) rutting

The figures show the cumulative road damage progression starting from zero defects up until the road's failure. Accordingly, every 36,000 cycles are equivalent to one month's period of trafficking and. At the beginning of the loads, cumulative rutting was gradually increasing and thence automatic accelerated fatigue progression after approximately $1 / 3$ of the pavement life. Four million cycles are equivalent to 9.3 years of trafficking. As shown in the figure, roads with IRI equal to 2 remain for more cycles than those with a higher IRI approximately more than 3.9 million to 4.1 million. In apart, the road with the IRI=3.5 endures for up to 2.9 million or 8.36 years before it fails compared to roads that have an IRI $=2$ which remain for approximately 11.6 to 12.1 years.

Consequently, it is clear that the initial IRI of the road significantly influences pavement life [24], [25]. The number of cycles leading up to failure and the failure mechanism of the roads are all given in Table III. The failure mechanism that dominates all road types is rutting. The life amongst the roads with an IRI=2 varies between approximately $1.6 \%$ and $6.5 \%$. However, the percentage differences increase when comparing the average cycles with $I R I=2, \quad I R I=2.5, \quad I R I=3$ and $I R I=3.5$. They are estimated as $10.5 \%, 19.7 \%$ and $27.7 \%$, respectively. Also, for all roads, the cumulative fatigue at failure is lower than approximately 0.4 .

TABLE III

MODES OF FAILURES

\begin{tabular}{|c|c|c|c|}
\hline Road name & $\begin{array}{c}\text { Number of } \\
\text { axles to failure }\end{array}$ & $\begin{array}{c}\text { Failure } \\
\text { mechanism }\end{array}$ & $\begin{array}{c}\text { Cumulative } \\
\text { fatigue at } \\
\text { failure } \\
\text { condition }\end{array}$ \\
\hline Road1 & 3997177 & \multirow{9}{*}{ Rutting } & \multirow{9}{*}{$0.38-0.4$} \\
\hline Road2 & 3998323 & & \\
\hline Road3 & 3998652 & & \\
\hline Road4 & 3816169 & & \\
\hline Road5 & 4062323 & & \\
\hline Road6 & 3966249 & & \\
\hline Road7 & 3557517 & & \\
\hline Road8 & 3193746 & & \\
\hline Road9 & 2872378 & & \\
\hline
\end{tabular}

Also drawn in the figures, more fatigue occurs after cumulative rutting of $0.02 \mathrm{~m}$. This is due to generated rutting on the pavement increasing the loading undulation on the surface in turn, increasing the response in the pavement (tensile strain at the bottom of the asphaltic layer) and thus, accelerating pavement damage. It can be seen from the figure that for Roads 1 to 6 that are IRI equal to 2, pavement fails because of excessive rutting after an approximate range between 3.8 million and 4.1 million load passes. However, for other roads, the pavement would take approximately 3.6 million, 3.2 million and 2.9 million load passes to fail. This is for $\operatorname{Road} 7, \operatorname{Road} 8$, and Road9, respectively.

In conclusion, the life of a pavement is significantly affected by the initial roughness index. Roads with a different profile but the same initial IRI $=2$ do not have any significant variation in predicted life, that is lower than $6.5 \%$. However, there is a preferably linear decrease of the pavement's life from approximately 9.2 years to 8.3 years when the initial IRI value is increased from 2 to 2.5 . Thence, when the initial IRI increases to 3 , the life will shorten to about 7.4 years and 6.7 years when the IRI=3.5.

\section{B. Damage Propagation as a Function of Time Increment}

This section aims to determine an efficient time step that could reduce running time while maintaining accuracy. For that purpose, the incremental damage was simulated 
following a monthly evaluation for up to a year. The input, therefore, included temperature, and several groups of temperature data were obtained statistically, i.e., mean and standard deviation. Otherwise, monthly axle numbers were determined and were constant for all cases.

Figure 7(a-b) shows the cumulative damage when different statistical temperature evaluations are used. To measure the accuracy of the simulation, the cumulative monthly damage results from the simulations are compared with the cumulative hourly damage. As shown, the cumulative rutting and fatigue damage using monthly vehicles and monthly temperature averages is significantly lower than the cumulative rutting and fatigue using hourly vehicles and temperatures. Alternatively, using the monthly vehicle and average plus standard deviation monthly temperature results in a slight difference with the cumulative damage using the hourly vehicle and temperature data.

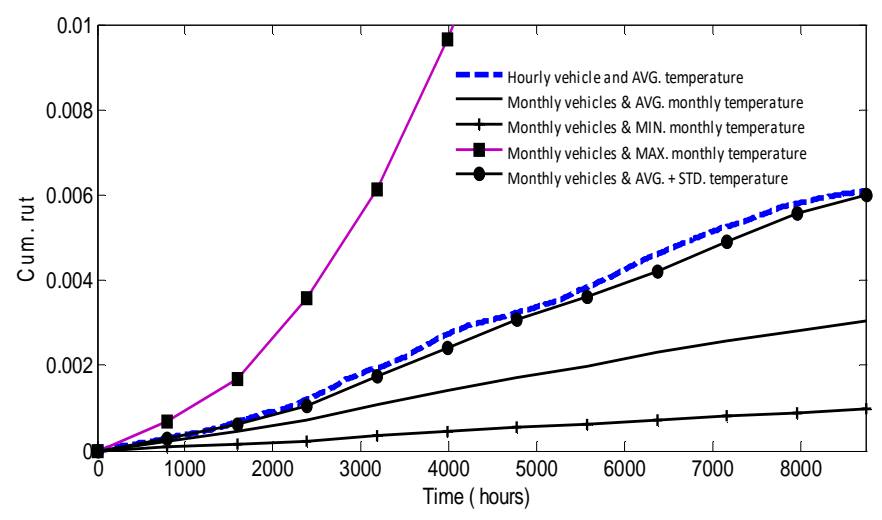

(a)

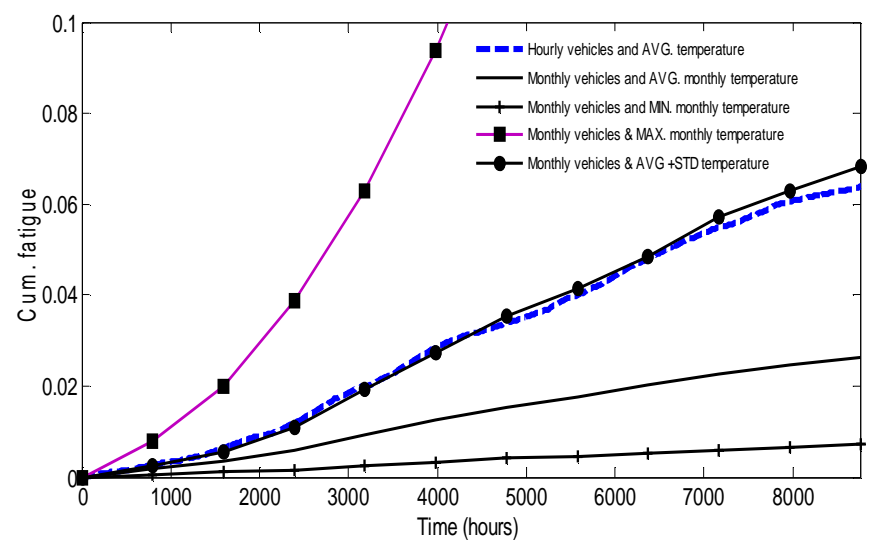

(b)

Fig. 7 Cumulative damage; (a) rutting and (b) fatigue

\section{CONCLUSIONS}

In conclusion, the cumulative damage is significantly comparable by a difference IRI value of road profiles. Higher IRI value resulted in more damage and vice versa. In all conditions, vehicles speed is the crucial factor in generating dynamic load. Also, as a function of time increment that directly varies the temperature, the viscous and elastic characteristics of the material control the deformation behavior of the asphalt layer in high temperature. Thence, the higher asphaltic surface temperature will lower elastic modulus of the surface layer and in turn, increase the critical strains in the pavement, also affecting an increment in damage progression. It is also noticed, time increment is one of the factors that should be seriously considered for predicting pavement life.

\section{ACKNOWLEDGMENT}

The authors would like to thank the Universiti Tun Hussien Onn Malaysia for funding this research.

\section{REFERENCES}

[1] Ullidtz, P. and Larsen, B. K., 1983, "Mathematical model for predicting pavement performance," Transportation Research Board, 949: pp. 45-55, 1999.

[2] Brademeyer, B. D., Delatte, N. J. and Markow, M. J., "Analysis of moving dynamic loads on highway pavements, Part II: Pavement response," Int. Symposium on Heavy Vehicle Weights and Dimensions, Kelowna, British Columbia, Canada, 1986.

[3] Ullidtz, P., "Mathematical model of pavement performance under moving wheel load," Presented at 72nd Annual Meeting of the TRB, Washington DC., 1993.

[4] Collop, A. C., "Effect of traffic and temperature on flexible pavement wear," Ph.D. thesis, Cambridge University Engineering Department, Cambridge UK. 1994

[5] Papagiannakis, A. T., "Calibration of WIM Systems, through dynamic vehicle Simulation," J. Of Testing and Evaluation, JTEVA, Vol. 25, No. 2: pp. 197-204., 1997.

[6] Mattarocci, M., "Un modello di degrade empirico-meccanicistico per la valutazione della irregolarita longitudinal nelle sovrastrutture stradali flesibili", PhD Thesis, Universita Degli Studi Di Napoli Federico.2006.

[7] NCHRP, "Guide for Mechanistic-Empirical design of new and rehabilitated pavement structures," National Cooperative Highway Research Program., 2004

[8] Buhari R., Aman M.Y., Rohani M.M., Puteh S. "Primary Response Of Pavement Variation With Construction Variables," ARPN Journal of Engineering and Applied Sciences, Asian Research Publishing Network, 2016,11818, ISSN:18196608

[9] Li, P.; Ding, Z.; Zhang, Z.,"Effect of Temperature and Frequency on Visco-Elastic Dynamic Response of Asphalt Mixture, Journal of Testing and Evaluation, 41(4), pp. 571-578, 2013.

[10] Wayessa, S. G., Quezon, E. T., \& Kumela, T., "Analysis of StressStrain and Deflection of Flexible Pavements Using Finite Element Method Case Study on Bako-Nekemte Road," 2(4), 100-111., 2017.

[11] Rahman, M.T.; Mahmud, K.; Ahsan, S., "Stress-Strain characteristics of flexible pavement using Finite Element Analysis," International Journal of Civil and Structural Engineering, 2 (1), pp. 233-240, 2011.

[12] Vukobratović, N.,"Stress and strain analyses in the asphalt pavements," Final thesis, Faculty of Civil Engineering Osijek, in Croatian, 2014.

[13] Brown, S. F., and Brunton, J. M., "An introduction to the analytical design of bituminous pavements," ${ }^{\text {rd }}$ ed., Univ. Of Nottingham, Dept. of Civil Engineering, Nottingham UK., 1992.

[14] Choudhary, D. K.; Joshi, Y. P., "A Detailed Study of CBR Method for Flexible Pavement Design," International Journal of Engineering Research and Applications, 4 (6), pp. 239-253, 2012.

[15] Buhari R., Collop A.C., "Pavement Primary Response using Influence Function and Peak Influence Function," Applied Mechanics and Materials, Vols. 256-259, pp. 1871-1881., 2012.

[16] Rukavina, T.; Ožbolt, M.; Domitrović, "Influence of axle load on flexible pavement design (in Croatian), 5th Croatian Road Congress, Croatian Road Society - Via Vita, Cavtat, Croatia, Vukobratović, 2011.

[17] Miner, M. A., "Cumulative damage in fatigue." Trans., Am. Soc. Mech. Eng., 67, A159-A164., 1945

[18] JKR/SPJ/2008-S4, "Standard specification for road works, Section 4: Flexible Pavement, Malaysian Public Work Department, Malaysia. 2013.

[19] JKR ATJ/5/85 85 [Amendment 2013], Malaysian Public Work Department, Malaysia. 2013. 
[20] Brown, S. F., and Brunton, J. M., "An introduction to the analytical design of bituminous pavements," $3^{\text {rd }}$ ed., Univ. Of Nottingham, Dept. of Civil Engineering, Nottingham UK. 1992.

[21] Buhari R., Abdullah M.e., Rohani M.M., "Predicting Truck Load Variation Using Q-Truck Model," Applied Mechanics and Materials, Vol. 534, pp. 105-110, 2014

[22] Dodds, C. J., and Robson, J. D., "The description of road surface roughness,” J. Sound and Vibration, 31(2): pp. 175-183., 1973.
[23] Buhari R., "Longitudinal Road Profile Model Generation Based on Measurement Data using Mathematical Approach, Advanced Science Letters, Vol: 21, 12, 3627-3651, 2015.

[24] Dimter, S. "Analyses of the influence of material characteristics on pavement design by analytical and empirical methods," (14), 8-19., 2017

[25] El-Maaty Behiry, A.E.A. "Fatigue and rutting live in the flexible pavement," Ain Shams Engineering Journal, 3(4), pp. 367-374; https://doi.org/10.1016/j.asej.2012.04.008. 2012 